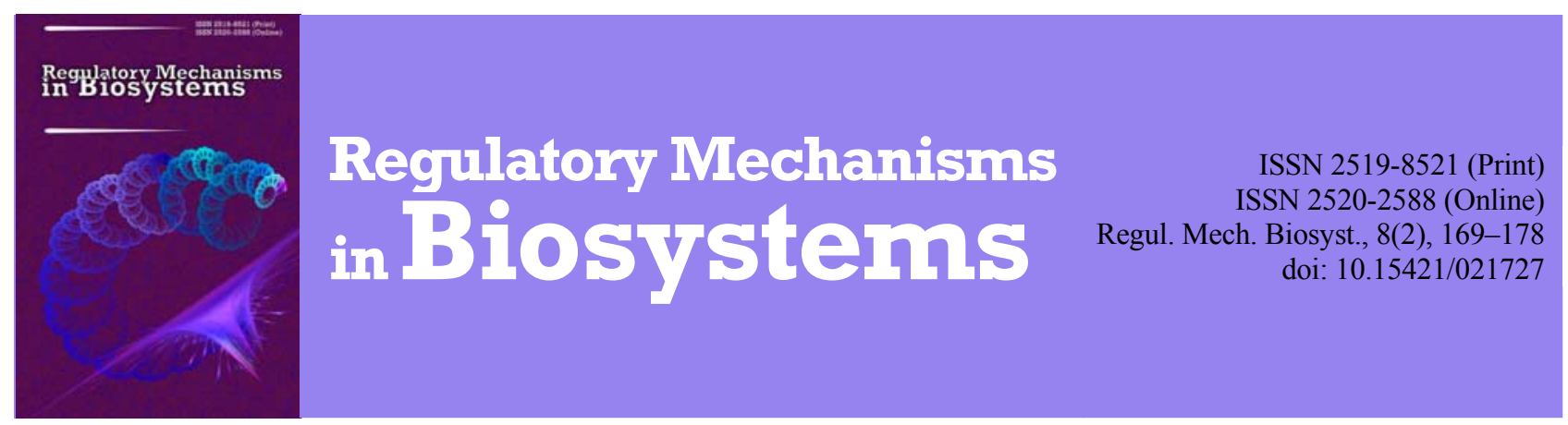

\title{
The compartments of the parenchyma of the lymph nodes in the newborn bull calves of domestic cattle (Bos taurus)
}

\author{
P. N. Gavrilin, O. G. Gavrilina, M. V. Kravtsova \\ Dnipro State Agrarian-Economic University, Dnipro, Ukraine
}

Article info

Received 29.03.2017

Received in revised form 22.04.2017

Accepted 29.04.2017

Dnipro State Agrarian-Economic University, Sergey Efremov Str., 25, Dnipro, 49600, Ukraine. Tel.:+38-099-545-33-31.

E-mail:

morfologagro@gmail.com
Gavrilin, P. N., Gavrilina, O. G., \& Kravtsova, M. V. (2017). The compartments of the parenchyma of the lymph nodes in the newborn bull calves of domestic cattle (Bos taurus). Regulatory Mechanisms in Biosystems, 8(2), 169-178. doi:10.15421/021727

The article analyzes the features of the structure of the lymphoid lobules of the parenchyma of the superficial somatic (Limphonodi subiliaci, L. cervicales superficiales), profund somatic (L. axillares proprii L. poplitei), somatovisceral (L. iliaci mediales, L. retropharyngei mediales) and visceral (L. mediastinales caudales, L. ileocolici) lymph nodes of newborn bull calves of domestic cattle. To visualize clearly the boundaries of the structural components of lymphoid lobules we used the author's modification of the impregnation of total median frozen histological sections with silver nitrate. We have established a high level of tissue differentiation of the lymph nodes, a significant development of the lymphoid parenchyma, the division of the parenchyma into lymphoid lobules, the presence in the lobules of all the main structural components that are represented by two morphotypes. The first morphotype is ribbonlike perisinusoidal cords (interfollicular zone, paracortical and medullary cords). The second morphotype is rounded lymphoid formations (central zones of deep cortex units, lymphatic nodules). Lymphoid lobules are located along the marginal sinus in one row, they are better developed and differentiated in the visceral lymph nodes. In all the lymph nodes, the lymphoid lobules have a similar histoarchitectonics, and each structural component of the lymphoid lobules has a specific architectonics of the reticular meshwork and the density of the location of the fibroblastic reticulocytes. We determined that the structures of the first morphotype which provide the migration of lymphocytes, the detection of antigens and the accumulation of plasmocytes are more developed. We have established that the relative volume of structures of the first morphotype is 4.5-8.0 times larger than the volume of the structures of the second morphotype, which provide clonal proliferation of T and B lymphocytes, especially in deep somatic lymph nodes. Among the zones of the second morphotype, predominate T-dependent zones, the relative volume of which considerably exceeds the volume of B-dependent zones (lymphoid nodules): in the superficial somatic lymph nodes by 14-30 times, profound somatic by $12-14$ times, somatovisceral by 6-7 times and visceral by $4.5-5.5$ times. We determined that lymphatic nodules can form in different parts of compartments: in the interfollicular zone and paracortical cords of all lymph nodes and in the medullary cords of the visceral lymph nodes. The study shows that the parenchyma of the lymph nodes of newborn bull calves has a high degree of maturity, contains a full set of structural markers of immunocompetence, among which predominate the components that support lymphocyte migration, antigen detection and accumulation of plasma cells.

\section{Компартменты паренхимы лимфатических узлов у новорожденных особей быка домашнего (Bos taurus)}

\author{
П.Н.Гаврилин, Е. Г. Гаврилина, М. В. Кравцова
}

Днепровский государственный аграрно-экономический университет, Днепр, Украина

Проанализированы особенности строения компартментов (лимфоидных долек) в паренхиме различных групп лимфатических узлов у новорожденных особей быка домашнего. Для одновременной визуализации структурных компонентов лимфоидных долек использовали авторскую модификацию импрегнации тотальных срединных замороженных срезов азотнокислым серебром. Лимфоидная паренхима всех групп лимфатических узлов имеет выраженную дольчатую структуру. Компоненты лимфоидных долек подразделяются на два основных морфотипа. Первый морфотип представлен лентообразными перисинусоидальными тяжами (интерфолликулярная зона, паракортикальные и мозговые тяжи), которые обеспечивают миграцию лимфоцитов, детекцию антигенов и аккумуляцию плазмоцитов. Второй морфотип представлен округлыми образованиями (центральные зоны единиц глубокой коры или Т-зависимые зоны, лимфатические узелки или В-зависимые зоны), отвечающие за клональную пролиферацию лимфоцитов. Относительный объем структур первого морфотипа в 4,58,0 раз превышает объем структур второго морфотипа. Структуры первого морфотипа развиты относительно равномерно, а среди зон второго морфотипа преобладают Т-зависимые зоны (в 4,5-30,0 раз больше объема В-зависимых зон). Лимфатические узелки являются 
топографически нестабильными компонентами лимфоидных долек, формируються на основе всех видов тяжей лимфоидной паренхимы, и, в том числе, мозговых тяжей висцеральных лимфатических узлов.

Ключевые слова: лимфоидные дольки; единицы глубокой коры; паракортикальные и мозговые тяжи; лимфоидные узелки

\section{Введение}

Лимфатические узлы у млекопитающих являются универсальными биологическими фильтрами, которые обеспечивают антигенный контроль тканевой жидкости и лимфы, формируют в различных частях организма скопления или лимфоцентры, специализированные и адаптированные к особенностям потенциального регионального антигенного прессинга (Ikomi et al., 2012; Jafarnejad et al., 2015; Houston et al., 2016). Помимо региональной специализации, для лимфатических узлов характерна внутриорганная дифференциация паренхимы, что морфологически выражается в ее дольчатой или дискретной структуре. На сегодня не существует универсального термина для обозначения структурных единиц паренхимы лимфатических узлов. Ряд авторов называет структурно-функциоанльные единицы паренхимы компартментами (Belisle and Sainte-Marie, 1981; Sainte-Marie, 2010), другие обозначают их как лимфоидные дольки (Kelly, 1975; Gretz et al., 1997; Willard-Mack, 2006). Необходимо отметить, что термин «лимфоидная долька» является более предпочтительным и используется не только в морфологии, но и в области патологии и онкологии (Elmore, 2006; Chandrasekaran and King, 2014; Shipman et al., 2017). Лимфоидные дольки в лимфатических узлах относятся к основным структурно-функциональным единицам, аналогично нефронам в почках или долькам в печени, а изменения данных единиц в зависимости от возраста или локализации узлов, в эксперименте, а также при воздействии различных антигенов наиболее точно и адекватно отражают суть и характер развивающихся в узлах процессов от нормы реакции до патологических состояний (Elmore, 2000; Willard-Mack, 2006; Margaris and Black, 2012).

Основным объектом при разработке современной гистологической терминологии лимфатического узла (Kowala and Schoefi, 1986; Konenkov et al., 2008; Ohtani and Ohtani, 2008), a также исследовании функциональных изменений в лимфатических узлах, в том числе при различных болезнях, являются соответствующие органы лабораторных животных (белые мыши, крысы) и приматов (Iwasaki et al., 2016; Palm et al., 2016; Lee et al., 2017). В результате установлено, что лимфоидные дольки в лимфатических узлах располагаются в один ряд и ограничиваются друг от друга поперечными лимфатическими синусами. Субъединицы паренхимы лимфатических узлов или лимфоидные дольки имеют форму неправильного овала, расширенная вершина которого обращена в сторону краевого синуса, а суженная, образованная мозговыми тяжами с сосудистой ножкой в сторону воротного синуса и, соответственно, ворот узлов в целом (Willard-Mack, 2006). Количество долек в паренхиме того или иного узла определяется числом впадающих в краевой синус приносящих лимфатических сосудов по принципу: один лимфатический сосуд - одна лимфоидная долька (Belisle and Sainte-Marie, 1981; Sainte-Marie, 2010). Структурно-функциональная единица паренхимы лимфатических узлов млекопитающих или лимфоидная долька имеет целый ряд принципиальных отличий от субъединиц других органов. В структурно-функциональном отношении лимфоидная долька относительно стабильна, ее развитие и структурная перестройка имеют реактивный характер и определяются, прежде всего, интенсивностью антигенного воздействия на соответствующий регион или особенностями патогенеза иммунопатологических процессов (Olson et al., 2012; Azzi et al., 2016). Лимфоидная составляющая паренхимы в лимфоидной дольке лабильна вследствие активной рециркуляции лимфоцитов и антигенпрезентирующих клеток (Jia et al., 2012; Platt and Randolph, 2013; Butler et al., 2016).

Структура и цитоархитектоника стабильной компоненты лимфоидной дольки представлена скоплениями фибробласти- ческих ретикулярных клеток и сетей, образуемых ими ретикулярных волокон различной плотности. Ретикулярная строма лимфоидной дольки чрезвычайно разнообразна и формирует вместе с сосудами микроциркуляторного русла ряд специализированных зон, которые обеспечивают расселение, взаимодействие с антигенпрезентирующими клетками и клональную пролиферацию лимфоцитов (Kaldjian et al., 2001; Andrian and Mempel, 2003; Sixt et al., 2005).

В лимфоидной дольке паренхимы лимфатического узла млекопитающих принято выделять такие структурно-функциональные зоны: единицы глубокой коры (центральные зоны единиц), которые сверху и с боков окружены, соответственно, интерфолликулярной зоной (корковое плато) и паракортикальными тяжами (периферические зоны единиц) (Kelly, 1975). В направлении ворот лимфатических узлов единицы глубокой коры без явных границ переходят в мозговые тяжи. Периферия единиц глубокой коры или «транзитная зона» содержит венулы с высоким эндотелием и обеспечивает процессы миграции лимфоцитов в паренхиму узлов (De Bruyn and Cho, 1990; Ruddle, 2016; Ager, 2017). На основе интерфолликулярной зоны вдоль краевого синуса формируются первичные и вторичные лимфатические узелки (зоны локализации и клональной пролиферации В-лимфоцитов), тогда как центр единиц глубокой коры относится к участкам локализации и клональной пролиферации Т-лимфоцитов (Rouse et al., 1984; Katakai et al., 2004; Capece and Kim, 2016). Мозговые тяжи, расположенные в области ножки лимфоидной дольки, являются основной зоной локализации плазматических клеток и, соответственно, образования иммуноглобулинов (Andrian and Mempel, 2003).

Концепция о лимфоидной дольке лимфатических узлов млекопитающих как их базовой структурной единицы до настоящего времени не является общепризнанной и общепринятой. Существенным препятствием для ее окончательного утверждения в биологии и медицине является всестороннее обоснование данного представления, базирующегося на результатах исследования разных аспектов структуры паренхимы лимфатических узлов у разных видов млекопитающих. Имеющиеся на сегодняшний день в научной литературе сведения о строении лимфатических узлов парнокопытных млекопитающих, таких как домашние бык и свинья (Hoshi et al., 1986; Nicander et al., 1991; Gavrilin et al., 2013), верблюд одногорбый (Zidan and Pabst, 2012), часто не согласуются с вышеуказанной концепцией строения данных органов у приматов и лабораторных животных.

Исходя из того, что положение о лимфоидной дольке было разработано при исследовании лимфатических узлов у представителей млекопитающих с менее совершенной с эволюционной точки зрения морфофункциональной организацией, изучение структуры паренхимы лимфатических узлов парнокопытных имеет особый интерес. Исследование лимфатических узлов копытных млекопитающих, имеющих более совершенные интегрирующие системы, также составляет определенный практический интерес, так как многие из парнокопытных являются продуктивными животными, испытывающими действие неблагоприятных антропогенных факторов, подверженными ряду инфекционных болезней и различным видам иммунопатологии. Кроме того парнокопытные характеризуются зрелорождаемостью, что, безусловно, отражается на статусе органов кроветворения и иммунной защиты новорожденных особей, а также имеют особый тип строения плаценты (десмохориальная плацента), которая в норме практически непроницаема для материнских антигенов. Это, соответственно, исключает возможность формирования полноценного материнского иммунитета I типа (Geptner et al., 1961; Koliakov, 1986). 
Цель первого этапа нашей работы - определить особенности строения компартментов (лимфоидных долек) паренхимы интактных (не контактировавших с антигенами внешней среды) лимфатических узлов различной локализации новорожденных особей (телят) быка домашнего на макро-микроскопическом и тканевом уровне.

\section{Материал и методы исследований}

Материал для исследований отбирали от 6 новорожденных телят быка домашнего (Bos taurus), погибших во время родов по причинам, не связанным с инфекционными, инвазионными и незаразними болезнями (асфиксия вследствие ущемления пупочного канатика, аспирация плодных вод, асфиксия вследствие слабой родовой деятельности и т. д.). Материал для исследований - лимфатические узлы различной локализации: поверхностные соматические: подподвздошные (Limphonodi subiliaci), поверхностные шейные (L. cervicales superficiales); глубокие соматические: подмышечные (L. axillares proprii), подколенные (L. poplitei); висцеральные: каудальные средостенные (L. mediastinales caudales), подвздошноободочные (L. ileocolici); смешанные или сомато-висцеральные: медиальные заглоточные (L. retropharyngei mediales), медиальные подвздошные (L. iliaci mediales) (Zelenevsky, 2013). Учитывая, что все лимфатические узлы, за искючением висцеральных, являються парными органами, всего исследовано 84 органа.

Материал исследовали в Днепровском государственном аграрно-экономическом университете. Отобранные целые органы фиксировали в $5 \%$ охлажденном растворе формалина $\left(+4{ }^{\circ} \mathrm{C}\right)$ в холодильной камере в течение 48 часов. Дальнейшую фиксацию проводили при комнатной температуре в $10 \%$ растворе формалина в течение 10-14 суток. Учитывая, что исследуемые лимфатические узлы новорожденных телят быка домашнего имеют значительную массу и, соответственно, линейные размеры (длина - 20-50, ширина - 11-18 мм) (Gavrilin, 2000) для изготовления тотальних гистопрепаратов от каждого лимфатического узла после фиксации отбирали срединные сегменты в плоскости, перпендикулярной их воротам. Отобранные сегменты органов промывали в проточной воде в течение 2-3 суток для максимального удаления формалина. Тотальные срединные срезы лимфатических узлов толщиной 10-20 мкм изготавливали на микротоме-криостате с применением глицерин-желатиновых смесей. Из каждого сегмента получали 10 тотальных серийных срезов. Срезы импрегнировали нитратом серебра (5 срезов) и окрашивали гематоксилином и эозином (5 срезов). При изготовлении и окраске срезов за основу брали традиционные гистологические методики в авторской модификации (Gavrilin, 1999). Использование авторской модификации изготовления, окраски и импрегнации тотальних срезов лимфатических узлов позволило получить гистопрепараты с высокой степенью сохранности стромы и лимфоидной паренхимы, а также четкой и одновременной визуализацией структур лимфоидных долек по характерным особенностям строения сетей ретикулярных волокон.

Гистопрепараты исследовали на световых мироскопах Olympus CX-41 и Leica DM1000 (окуляр ${ }^{\mathrm{x}} 10$, объективы ${ }^{\mathrm{x}} 10$, х 40 ). В гистопрепаратах, окрашенных гематоксилином и эозином, определяли комплекс качественных характеристик исследуемых органов: степень развития и дифференцировки паренхимы узлов, особенности гистоархитектоники лимфоидных долек и характер взаимоотношений отдельных компонентов в их пределах. В этих же гистопрепаратах проводили измерения абсолютних размеров (максимальный диаметр) лимфатических узелков на микроскопе биологическом стереоскопическом (МБС-10), используя окуляр ${ }^{\mathrm{x}} 8$ со шкалой, объективы ${ }^{\mathrm{x}} 4$ и ${ }^{\mathrm{x}} 7$.

В гистопрепаратах, импрегнированных нитратом серебра, определяли количество лимфоидных долек на всей площади тотальных срезов, а также процентную объемную потность или относительный объем $(\mathrm{V}, \%)$ лимфоидной ткани в лимфа- тических узлах в целом и совокупный относительный объем отдельных компонентов лимфоидных долек: интерфолликулярные зоны (корковое плато), единицы глубокой коры: паракортикальные тяжи (периферические зоны единиц глубокой коры), центральные зоны единиц глубокой коры, лимфатические узелки с центрами и без центров размножения, мозговые тяжи. Количественно вышеуказанные компоненты анализировали методом «точечного счета» (Avtandilov, 1990) с использованием окулярных тестовых систем и нанесенными равноудаленными точками (100 точек) на всей площади гистопрепарата. Относительный объем компонентов лимфоидной паренхимы лимфатических узелков вычисляли по формуле:

$$
V=P_{i} / P_{t} \cdot 100 \% \text {, }
$$

где $V$ - относительный объем компонента, $P_{i}$ - число точек, попавших на структурный компонент, $P_{t}$ - общее число точек тестовой системы, попавших на гистопрепарат.

Необходимое для получения достоверных данных число точек $\tilde{n}$ (минимальный размер выборки, при котором выборочные наблюдения отклоняются от значений для генеральной совокупности не больше чем на $5 \%$ ), определяли по формуле:

$$
\tilde{n}=400(100-n) / n,
$$

где $n$ - число точек, приходящихся на анализируемый компонент при предварительном подсчете 100 точек (Avtandilov, 1990).

Микрофотографии изготавливали с использованием микроскопа Leica DM1000 (окуляр ${ }^{\mathrm{x}} 4$, объектив ${ }^{\mathrm{x}} 10 / 0,25,{ }^{\mathrm{x}} 40 / 0,65$ ), интегрированного с персональным компьютером.

Результаты исследований статистически обработаны и представлены с помощью Statistica 12.0 (StatSoft Inc., USA). Bepoятность разницы значений в различных группах лимфатических узлов оценивали при помощи t-критерия Стьюдента $(\mathrm{P}<0,05)$ после проверки нормальности распределения выборок.

\section{Результаты и их обсуждение}

Для лимфатических узлов новорожденных телят быка домашнего характерна высокая степень тканевой дифференциации с четким подразделением на строму (капсула, трабекулы, воротное утолщение капсулы), лимфатические синусы и лимфоидную паренхиму. Относительный объем лимфоидной паренхимы в различных лимфатических узлах значительно варьирует: менее всего ее содержится в глубоких соматических лимфатических узлах, затем следуют поверхностные соматические и соматовисцеральные узлы. В висцеральных лимфатических узлах количество лимфоидной паренхимы максимально (табл.). Полученные результаты свидетельствуют, что уже в плодном периоде пренатального онтогенеза паренхима лимфатических узлов у плодов быка домашнего развивается неравномерно. Изменение количественных характеристик лимфоидной паренхимы периферических лимфоидных органов имеет реактивный характер (Gretz et al., 1997; Vyrenkov et al., 1996). Степень увеличения объема лимфоидной ткани в периферических лимфоидных органах млекопитающих зависит от силы и интенсивности антигенного воздействия. Необходимо отметить, что у копытных млекопитающих с десмохориальным типом плаценты основными антигенными стимулами развития периферических лимфоидных органов являются аутоантигены. Можно предположить, что у плодов быка домашнего, как и особей в постнатальном онтогенезе, основным «поставщиком» антигенов являются слизистые оболочки и кожный покров. Источники и механизмы антителообразования у млекопитающих в пренатальном онтогенезе еще окончательно не установлены, а данная проблема является перспективным направлением исследований в иммунологии и иммуноморфологии.

Лимфоидная паренхима всех групп лимфатических узлов имеет выраженную дискретную или дольчатую структуру и состоит из относительно обособленных лимфоидных долек. Все лимфатические узлы представлены несколькими лимфоидными дольками, то есть являются поликомпартментными. Максимальное количество лимфоидных долек установлено в 
тотальных срезах соматовисцеральных лимфатических узлов. Минимальное количество данных структур характерно для подподвздошного и подмышечного лимфатических узлов, которые также имеют и минимальную абсолютную массу (Gavri- lin, 2000). Количество лимфоидных долек в поверхностном шейном, подколенном и каудальном средостенном лимфатическом узлах практически равнозначно (рис. 1).

\section{Таблица}

Относительный объем (\%) лимфоидной паренхимы и ее отдельных компонентов в лимфатических узлах различной локализации у новорожденных телят быка домашнего $(\mathrm{V} \pm \mathrm{m}, \mathrm{n}=6)$

\begin{tabular}{|c|c|c|c|c|c|c|c|c|}
\hline \multirow{4}{*}{ Лимфатический узел } & & \multirow{3}{*}{$\begin{array}{c}\text { Лимфоидная } \\
\text { паренхима }\end{array}$} & \multicolumn{6}{|c|}{ Лимфоидные дольки (компартменты) } \\
\hline & & & \multirow{2}{*}{$\begin{array}{c}\text { центральные зоны } \\
\text { единиц глубокой } \\
\text { коры }\end{array}$} & \multirow{2}{*}{$\begin{array}{c}\text { интерфолли- } \\
\text { кулярная зона }\end{array}$} & \multirow{2}{*}{$\begin{array}{c}\text { паракорти- } \\
\text { кальные тяжи }\end{array}$} & \multicolumn{2}{|c|}{ лимфатические узелки } & \multirow{2}{*}{$\begin{array}{c}\text { мозговые } \\
\text { тяжи }\end{array}$} \\
\hline & & & & & & $\begin{array}{c}\text { с центром } \\
\text { размножения }\end{array}$ & $\begin{array}{c}\text { без центра } \\
\text { размножения }\end{array}$ & \\
\hline & & I & II & III & IV & $\mathrm{V}$ & VI & VII \\
\hline Поверхностный шейный & $a$ & $\begin{array}{l}51,7 \pm \\
3,2^{c, d, f}\end{array}$ & $\begin{array}{c}7,25 \pm \\
0,15^{b-f, h}\end{array}$ & $\begin{array}{c}9,34 \pm \\
0,15^{b-d / f-h}\end{array}$ & $\begin{array}{c}13,62 \pm \\
0,72^{c, d, e-h}\end{array}$ & $\begin{array}{c}0,12 \pm \\
0,004^{b-h}\end{array}$ & $\begin{array}{c}0,12 \pm \\
0,06^{b, c, e-h}\end{array}$ & $\begin{array}{l}21,30 \pm \\
1,2^{c, d f-h}\end{array}$ \\
\hline Подподвздошный & $b$ & $\begin{array}{l}51,2 \pm \\
4,4^{c, d, f}\end{array}$ & $\begin{array}{c}8,05 \pm \\
0,12^{a, c, d-h}\end{array}$ & $\begin{array}{c}8,66 \pm \\
0,14^{a, c-h}\end{array}$ & $\begin{array}{c}13,12 \pm \\
0,52^{c, d_{f}-h}\end{array}$ & $\begin{array}{c}0,19 \pm \\
0,003^{a, c-f}\end{array}$ & $\begin{array}{l}0,36 \pm \\
0,03^{e-h}\end{array}$ & $\begin{array}{c}20,82 \pm \\
1,01^{c-h}\end{array}$ \\
\hline Подмышечный & $c$ & $\begin{array}{c}36,8 \pm \\
2,3^{a, b, d-h}\end{array}$ & $\begin{array}{c}4,22 \pm \\
0,06^{a, b, d-h}\end{array}$ & $\begin{array}{c}6,83 \pm \\
0,17^{a, b, e-h}\end{array}$ & $\begin{array}{c}9,09 \pm \\
0,34^{a, b, e, f}\end{array}$ & $\begin{array}{c}0,08 \pm \\
0,004^{a, b, d-h}\end{array}$ & $\begin{array}{c}0,28 \pm \\
0,02^{a, b, d-h}\end{array}$ & $\begin{array}{c}16,30 \pm \\
0,92^{a, b, d-h}\end{array}$ \\
\hline Подколенный & $d$ & $\begin{array}{c}31,7 \pm \\
2,2^{a-c, e-h}\end{array}$ & $\begin{array}{c}4,46 \pm \\
0,03^{a-c, e-h}\end{array}$ & $\begin{array}{c}6,66 \pm \\
0,13^{a, b, e-g}\end{array}$ & $\begin{array}{l}9,18 \pm \\
1,13^{a, b, f}\end{array}$ & $\begin{array}{c}0,03 \pm \\
0,001^{a-c, e-h}\end{array}$ & $\begin{array}{c}0,16 \pm \\
0,02^{b, c, e-h}\end{array}$ & $\begin{array}{c}11,21 \pm \\
0,19^{a-c, e-h}\end{array}$ \\
\hline Каудальный средостенный & $e$ & $\begin{array}{l}56,5 \pm \\
4,2^{c, d}\end{array}$ & $\begin{array}{c}9,33 \pm \\
0,14^{a-c, f-h}\end{array}$ & $\begin{array}{c}9,51 \pm \\
0,12^{b, c_{i}, g}\end{array}$ & $\begin{array}{l}11,24 \pm \\
1,16^{a, c h}\end{array}$ & $\begin{array}{c}0,58 \pm \\
0,02^{a-d, f-h}\end{array}$ & $\begin{array}{c}0,52 \pm \\
0,03^{a-d f f g}\end{array}$ & $\begin{array}{l}25,32 \pm \\
2,46^{b, c, d}\end{array}$ \\
\hline Подвздошноободочный & $f$ & $\begin{array}{l}65,6 \pm \\
6,8^{a-h}\end{array}$ & $\begin{array}{c}11,85 \pm \\
0,12^{\text {a-ce,g, } h}\end{array}$ & $\begin{array}{c}10,44 \pm \\
0,16^{a-c, e, g}\end{array}$ & $\begin{array}{l}11,57 \pm \\
0,39^{a-d, h}\end{array}$ & $\begin{array}{c}1,12 \pm \\
0,006^{a-e, g h}\end{array}$ & $\begin{array}{c}1,86 \pm \\
0,12^{a-e, g, h}\end{array}$ & $\begin{array}{c}28,76 \pm \\
2,6^{a-d}\end{array}$ \\
\hline Медиальный заглоточный & $g$ & $\begin{array}{l}50,8 \pm \\
4,4^{c, d f}\end{array}$ & $\begin{array}{c}7,11 \pm \\
0,16^{b, c, e f, h}\end{array}$ & $\begin{array}{c}7,53 \pm \\
0,18^{a-c, e f f}\end{array}$ & $\begin{array}{c}10,47 \pm \\
0,84^{a, b}\end{array}$ & $\begin{array}{c}0,20 \pm \\
0,008^{a, c-f, h}\end{array}$ & $\begin{array}{c}0,94 \pm \\
0,09^{a-f, h}\end{array}$ & $\begin{array}{c}24,55 \pm \\
1,16^{a-d}\end{array}$ \\
\hline Медиальный подвздошный & $h$ & $\begin{array}{l}49,2 \pm \\
3,4^{c, d f}\end{array}$ & $\begin{array}{c}6,36 \pm \\
0,08^{a-c, e-h}\end{array}$ & $\begin{array}{c}6,38 \pm \\
0,13^{a-c, e-g}\end{array}$ & $\begin{array}{l}9,20 \pm \\
0,12^{a, b}\end{array}$ & $\begin{array}{c}0,18 \pm \\
0,003^{a, c-g}\end{array}$ & $\begin{array}{c}0,56 \pm \\
0,04^{a-d, f-h}\end{array}$ & $\begin{array}{c}26,52 \pm \\
1,3^{a-d}\end{array}$ \\
\hline
\end{tabular}

Примечание: латинскими буквами обозначена статистическая вероятность разницы $\mathrm{P}<0,05$ относительного объема (V) в пределах отдельных групп структурных компонентов (I-VII) в различных лимфатических узлах $(a-h)$.
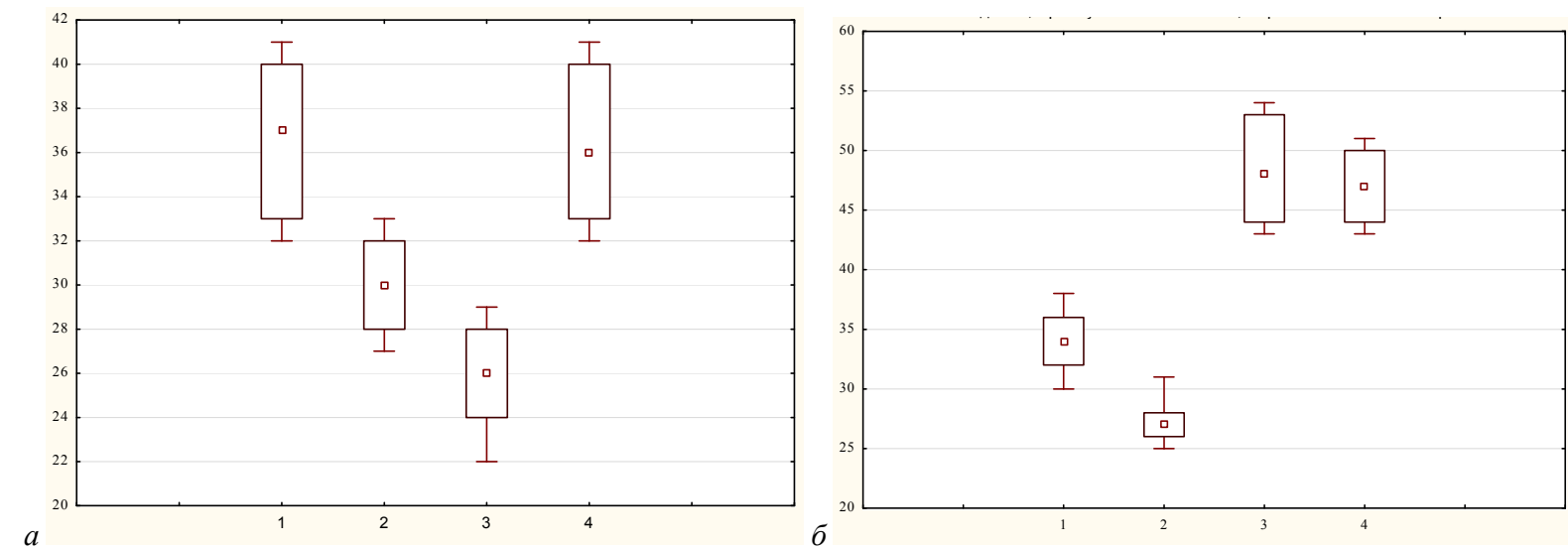

Рис. 1. Количество лимфоидных долек на площади тотальных срединных сегментальных срезов лимфатических узлов: $a$ - соматические лимфатические узлы: поверхностные ( 1 - поверхностный шейный, 2 - подподвздошный),

глубокие (3 - подмышечный, 4 - подколенный); 6 - висцеральные лимфатические узлы ( 1 - каудальный средостенный;

2 - подвздошноободочный); соматовисцеральные (3 - медиальный подвздошный; 4 - медиальный заглоточный); по оси абсцисс - лимфатические узлы, по оси ординат - количество лимфоидных долек (шт.)

Лимфоидные дольки в пределах срединных срезов лимфатических узлов развиты и распределены крайне неравномерно. Как правило, наиболее развитые лимфоидные дольки концентрируются в центре сегментов. Вышеуказанная разница наиболее выражена в соматических лимфатических узлах. Значительная вариабельность лимфоидных долек относительно их размеров и степени развития может быть обусловлена особенностями лимфоснабжения данных органов. Каждой отдельной дольке в паренхиме лимфатических узлов млекопитающих соответствует один афферентный лимфатический сосуд, объем лимфотока и концентрация антигенов в лимфе которого, вероятно, и определяют степень развития лимфоидных долек (Sainte-Marie, 2010). Преимущественная локализация наиболее развитых лимфоидных долек в центре сегментов лимфатических узлов также может быть связана с особенностями распределения корней афферентных лимфатических сосудов, с их концентрацией в определенных участках капсулы органов.
Лимфоидные дольки лимфатических узлов новорожденных телят по своим характеристикам, в основном, соответствуют аналогичным образованиям данных органов у лабораторных животных. Во всех без исключения лимфатических узлах лимфоидные дольки располагаются в один ряд, вдоль краевого синуса. С боков лимфоидные дольки ограничены промежуточными синусами, которые часто сопровождают капсулярные трабекулы. В результате этого граница между лимфоидными дольками более четко выражена в их апикальных участках. В связи с тем, что капсулярные трабекулы более развиты и выражены в соматических и соматовисцеральных узлах, дольковая структура паренхимы данных узлов проявляется более четко. В висцеральных лимфатических узлах, из-за слабого развития трабекулярного аппарата и вследствие незначительного просвета промежуточных синусов, граница между лимфоидными дольками слабо различима. Вследствие этого в пределах паренхимы висцеральных лимфатических узлов форми- 
руются «сросшиеся» боковыми поверхностями комплексы лимфоидных долек. В соматических лимфатических узлах лимфоидные дольки имеют преимущественно равномерную овальную форму с незначительными расширениями апикальной части. В висцеральных лимфатических узлах апикальная зона лимфоидных долек умеренно расширяется, что особенно характерно для узлов, расположенных в брюшной полости (рис. 2).

В составе лимфоидных долек паренхимы лимфатических узлов новорожденных телят обнаружены все без исключения компоненты, как и у половозрелых лабораторных животных. В гистологических препаратах данные компоненты представлены двумя основными морфотипами: лентообразными перисинусоидальными тяжами (интерфолликулярная зона, паракортикальные и мозговые тяжи) и округлыми образованиями (центральные зоны единиц глубокой коры или Т-зависимые зоны, лимфатические узелки или В-зависимые зоны) (Kaldjian et al., 2001). Степень развития соответствующих зон, как в целом в пределах паренхимы, так и среди отдельных лимфоидных долек имеет ряд существенных особенностей. Основным компонентом лимфоидных долек являются единицы глубокой коры, в которых четко различается округлая центральная зона, окруженная снаружи полукольцевидным участком паренхимы, обеспечивающим транзит лимфоцитов из сосудистого русла в паренхиму узлов. Данный участок представлен перисинусоидальными тяжами - корковым плато (интерфолликулярная зона) и периферической зоной глубокой коры (паракортикальными тяжами) (рис. 3). Корковое плато при этом является самостоятельной структурной единицей лимфоидных долек и граничит с краевым синусом, а паракортикальные тяжи относятся к периферическим участкам единиц глубокой коры и граничат, соответственно, с междольковыми или паракортикальными синусами.
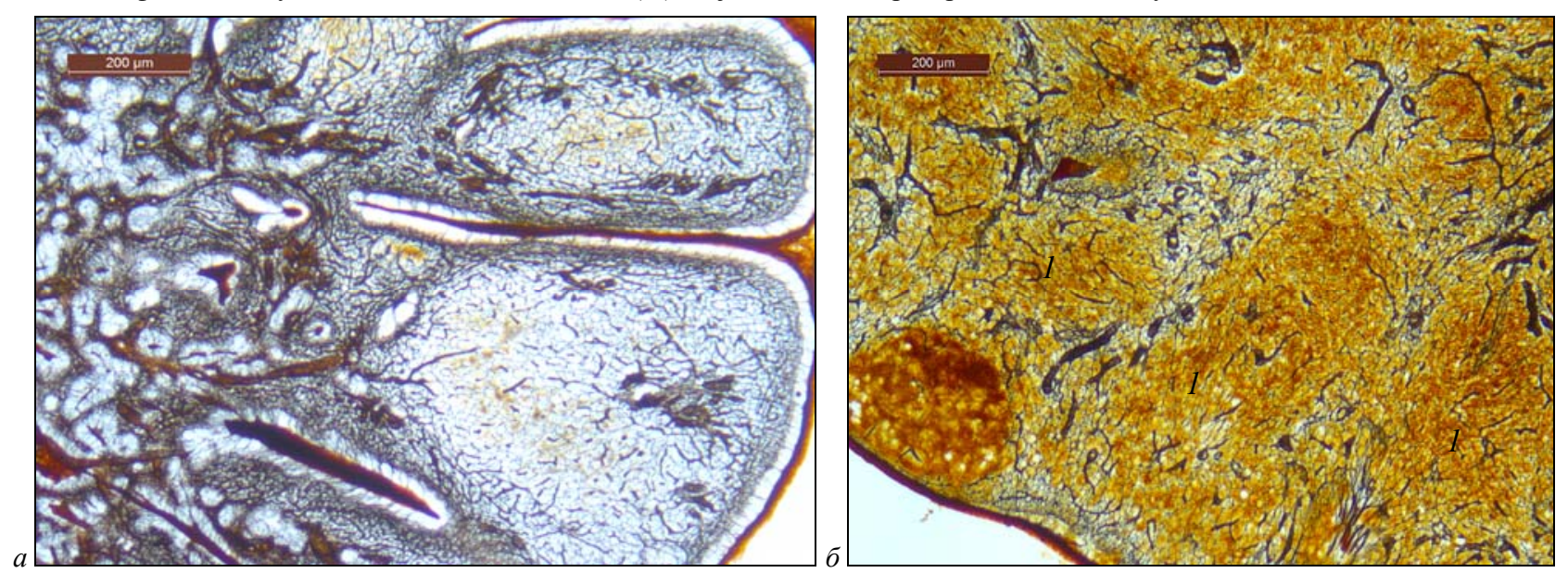

Рис. 2. Лимфоидные дольки в паренхиме соматических $(a)$ и висцеральных (б) лимфатических узлов: импрегнация азотнокислым серебром
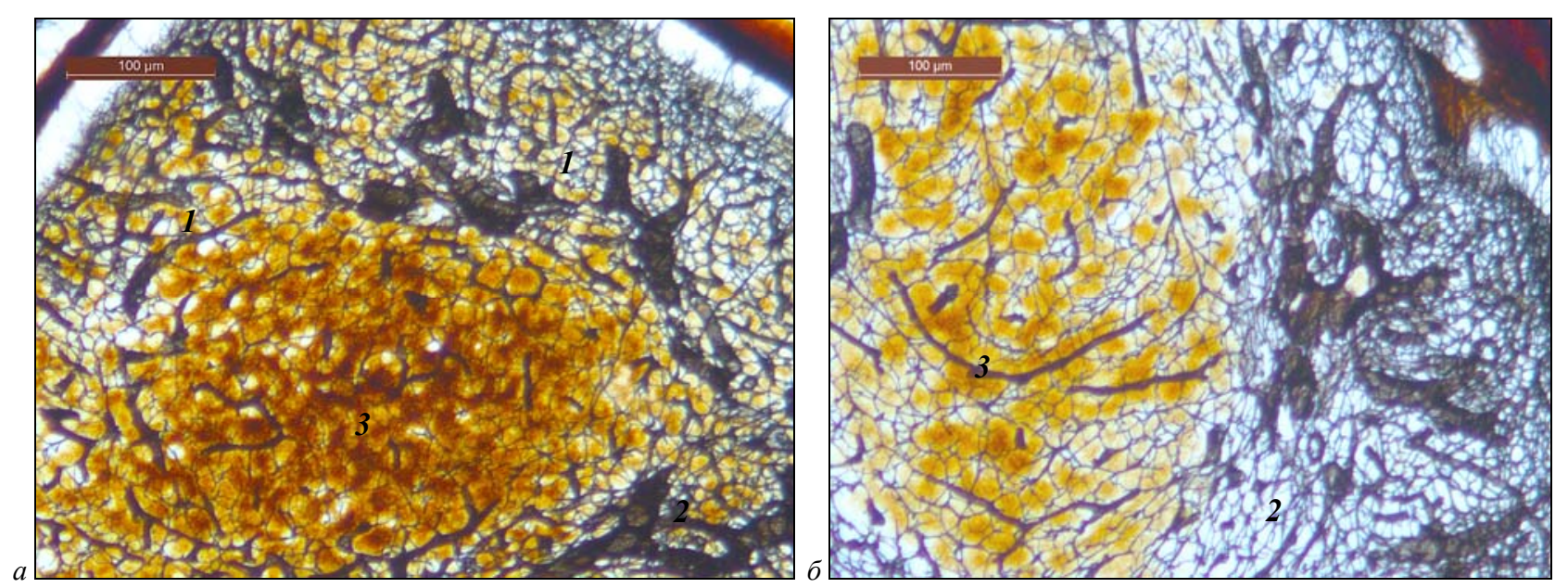

Рис. 3. Интерфолликулярная зона (1), паракортикальные тяжи (2) и центральная зона (3) единицы глубокой коры в поверхностном шейном (a) и подподвздошном (б) лимфатическом узле: импрегнация азотнокислым серебром

Плотность расположения фибробластических ретикулярных клеток и их отростков и, соответственно, ретикулярных волокон в различных участках лимфоидных долек значительно варьирует. В центральных зонах единиц глубокой коры ретикулярные волокна формируют равномерные широкопетлистые сети. В интерфолликулярных зонах и паракортикальных тяжах сети ретикулярных волокон абсолютно идентичны, преимущественно средне- и мелкопетлистые (рис. 4). Они образуют специфические ретикулярные уплотнения по всей периферии центральных зон единиц глубокой коры, за исключением их дистальных участков или кортико-медуллярного соединений, где происходит непосредственный контакт центральных зон единиц глубокой коры с мозговыми тяжами.
В гистопрепаратах, импрегнированных азотнокислым серебром в интерфолликулярных зонах и паракортикальных тяжах выявляется значительное количество кровеносных сосудов, в том числе и вен с высоким эндотелием (Sasaki et al., 1996; Ruddle, 2016; Ager, 2017).

Лимфатические узелки в лимфатических узлах новорожденных телят обнаруживаются в незначительных количествах не только в интерфолликулярной зоне, но и в паракортикальных тяжах. Для узелков без центров размножения характерны равномерные средне- и мелкопетлистые сети ретикулярных волокон. В узелках с центрами размножения ретикулярные сети их центральных участков в основном крупнопетлистые и плотные мелкопетлистые - в маргинальных зонах. Для мозго- 
вых тяжей лимфатических узлов новорожденных телят характерны плотные мелкопетлистые сети ретикулярных волокон, которые равномерно окружают расположенные в основе тяжей кровеносные сосуды (рис. 5).

Степень развития отдельных компонентов лимфоидных долек у новорожденных телят имеет ряд особенностей, что обусловлено специфическими условиями развития данных органов в условиях ограниченного антигенного влияния (Gunnes et al., 1998; Sapin, 2006). «Полноценная» иммунокомпетентность развивается у 4-5месячных плодов быка домашнего. Соответственно плоды данно-

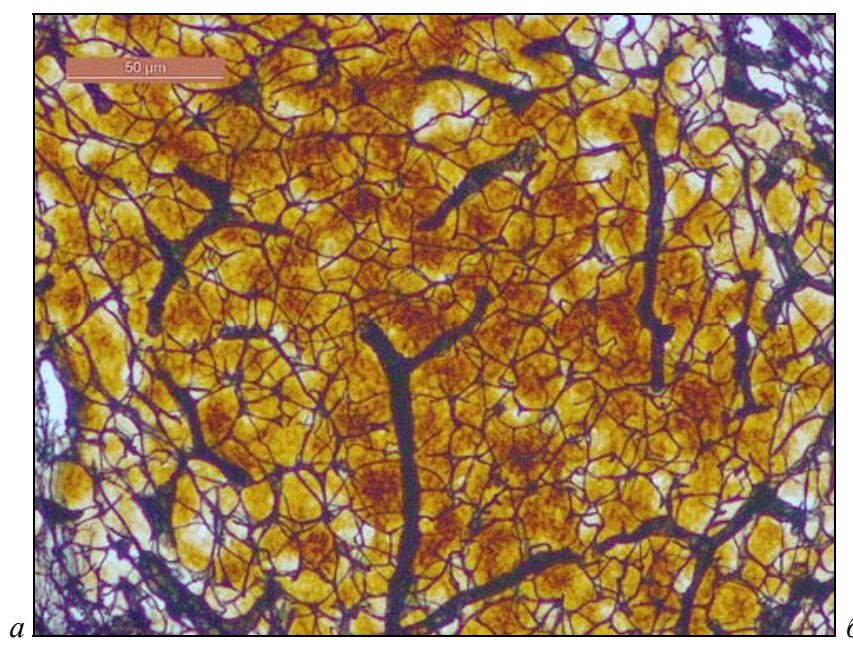

го возраста в состоянии адекватно реагировать на антигены и синтезировать антитела. По мнению исследователей (Buchvalder et al., 1981; Emeljanenko, 1987), развитие паренхимы вторичных лимфоидных органов у плодов млекопитающих связано как с воздействием на нее антигенов, проникающих через плацентарный барьер, так и собственных измененных белков, которые приобретают антигенные свойства. При этом влияние на лимфоидные органы обоих групп антигенов имеет крайне ограниченный характер, что, вероятно, и определяет особенности строения лимфоидных долек новорожденных особей млекопитающих.

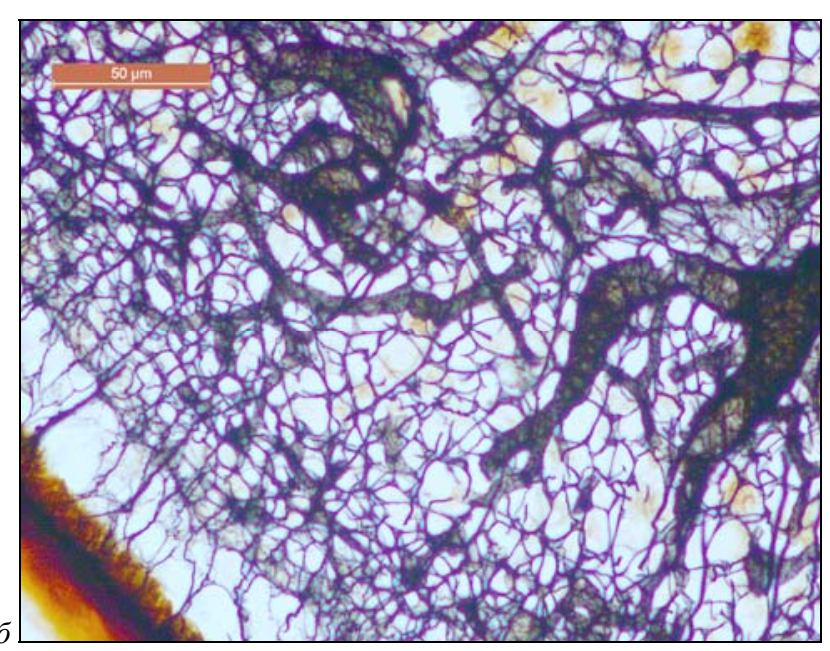

Рис. 4. Сети ретикулярных волокон в центральной зоне единицы глубокой коры (a) и интерфолликулярной зоне (б) медиального подвздошного лимфатического узла: импрегнация азотнокислым серебром
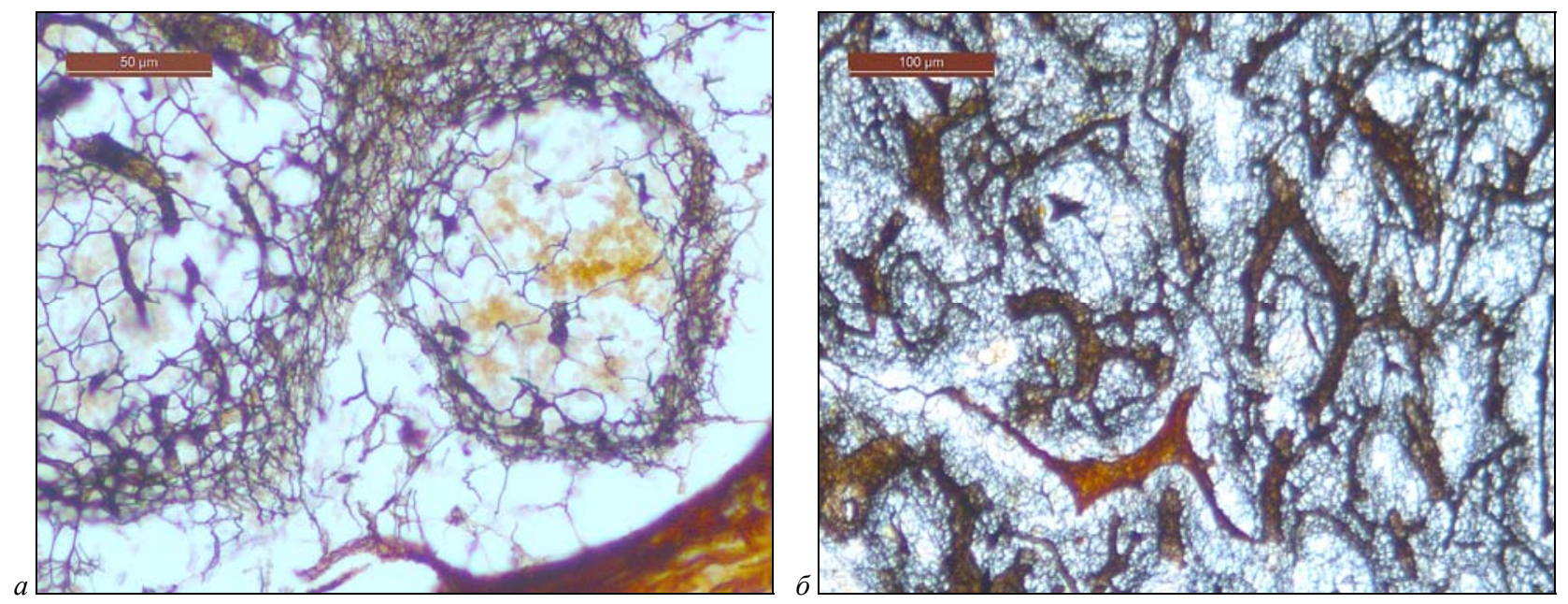

Рис. 5. Сети ретикулярных волокон в лимфатическом узелке (a) и мозговых тяжах (б) подмышечного лимфатического узла: импрегнация азотнокислым серебром

Результаты наших исследований свидетельствуют, что участки лимфоидных долек, в которых происходит антигензависимая клональная пролиферация и, соответственно, локализация субпопуляций Т- и В-лимфоцитов, развиты относительно слабо. При этом Т-клеточные зоны развиты в гораздо большей степени, чем В-клеточные. Относительный совокупный объем центральных участков единиц глубокой коры в лимфатических узлах различных групп варьирует от 4,2\% до 11,3\%. Максимальные его показатели характерны для висцеральных лимфатических узлов, минимальные - для глубоких соматических. Средние значения данного показателя установлены в поверхностных соматических и соматовисцеральных лимфатических узлах. Совокупный относительный объем транзитных зон (интерфолликулярная зона, паракортикальные тяжи) в среднем в 2-3 раза превышает соответствующий показатель зон пролиферации и локализации Т-лимфоцитов. Эта разница наиболее выражена в глубоких соматических узлах, несколько меныше - в поверхностных соматических и соматовисцеральных и менее всего - в висцеральных лимфатических узлах. При этом совокупный относительный объем интерфолликулярных зон практически равнозначен объему паракортикальных тяжей. Так, во всех исследованных лимфатических узлах относительный объем паракортикальных тяжей превышает объем интерфолликулярных 3он не более чем на 2-4\%. Совокупный относительный объем мозговых тяжей в лимфатических узлах различных групп новорожденных телят незначительно отличается от показателей совокупной площади транзитных зон. В большинстве соматических лимфатических узлов, за исключением подколенного, относительный объем транзитных зон и мозговых тяжей практически равнозначны. В соматовисцеральных и висцеральных лимфатических узлах относительный совокупный объем мозговых тяжей на 511\% превышает совокупный объем транзитных зон.

Лимфатические узелки в лимфоидной дольке лимфатических узлов новорожденных телят развиты незначительно. Их со- 
вокупный относительный объем в большинстве лимфатических узлов не превышает 1\% (за исключением висцеральных 1-3\%). Большая часть лимфатических узелков в паренхиме лимфатических узлов новорожденных телят относится к первичным, которые не содержат центры размножения.

Полученные результаты свидетельствуют, что в лимфоидных дольках паренхимы лимфатических узлов новорожденных телят обнаружены структуры, свидетельствующие об участии данных органов в реализации процессов антигензависимой клональной пролиферации Т- и В-лимфоцитов. В то же время основная масса лимфоидной паренхимы долек приходится на участки, обеспечивающие миграцию лимфоцитов, детекцию антигенов и аккумуляцию плазмоцитов. При этом уже у новорожденных животных различные зоны в лимфоидных дольках лимфатических узлов развиты крайне неравномерно, что зависит от локализации органов относительно кожи и слизистых оболочек.

Гистоархитектоника лимфоидных долек в лимфатических узлах новорожденных телят также весьма разнообразна и специфична. Топографически наиболее стабильными компонентами лимфоидных долек являются единицы глубокой коры. В соматических и соматовисцеральных лимфатических узлах

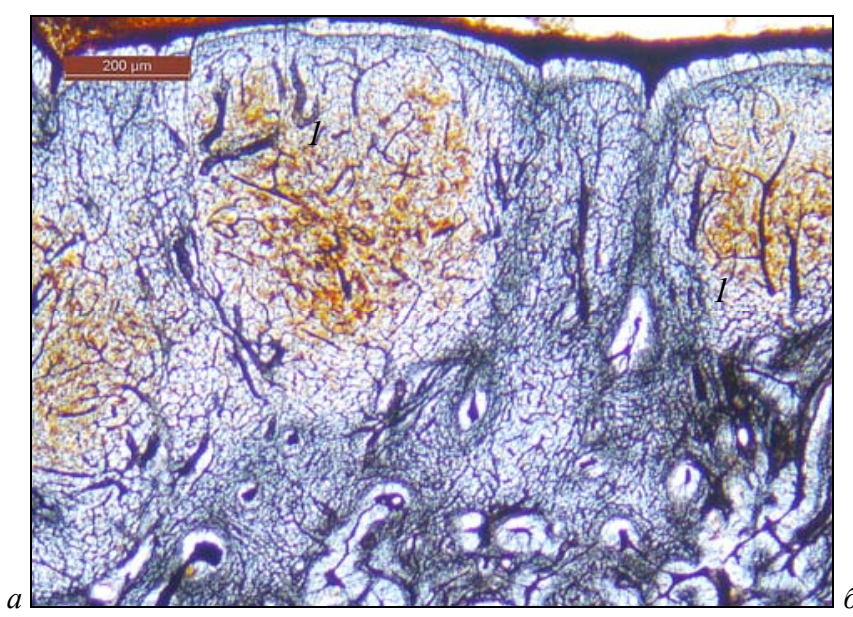

они образуют цепь неравномерных по объему утолщений на границе с мозговыми тяжами и выглядят как отдельные шарообразные структуры с характерной архитектоникой сетей ретикулярных волокон. В висцеральных лимфатических узлах единицы глубокой коры могут «срастаться» боковыми поверхностями (паракортикальными тяжами), образуя в некоторых участках гантелеобразные утолщения (рис. 6). В отдельных единицах глубокой коры центральные зоны могут формировать боковые выросты (выпячивания), которые, как правило, находятся у основания базовой единицы, создавая картину многоярусного расположения соответствующих структур.

Лимфатические узелки (как первичные, так и вторичные) в лимфоидных дольках большинства лимфатических узлов новорожденных телят формируются в интерфолликулярной зоне на границе с краевыми синусами. При этом отдельные лимфатические узелки вдаются в просвет синуса, что наиболее выражено в глубоких соматических лимфатических узлах (рис. 7).

Абсолютные размеры лимфатических узелков в лимфоидных дольках соматических узлов новорожденных телят варьируют. Максимальный диаметр лимфатических узелков характерен для висцеральных лимфатических узлов, а минимальный для глубоких соматических (рис. 8).

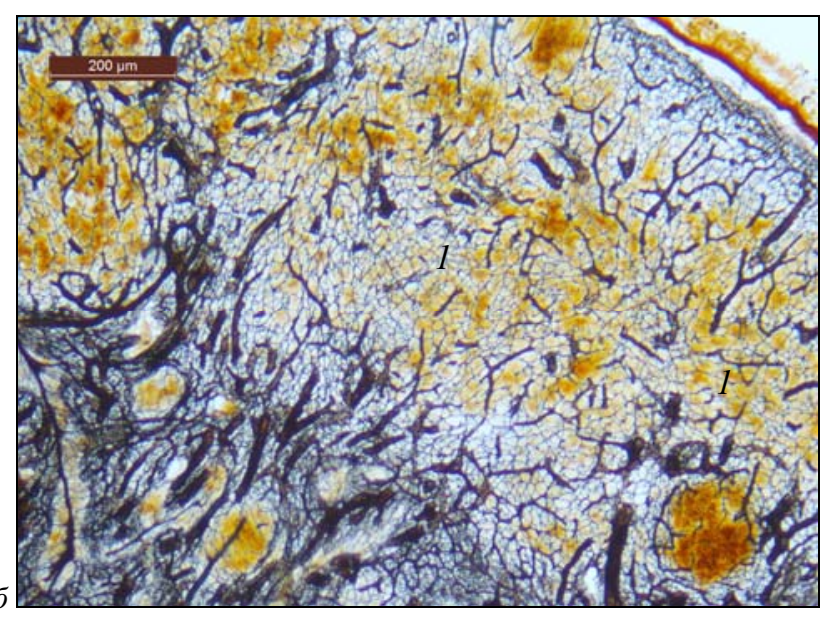

Рис. 6. Комплекс единиц глубокой коры (1) в соматическом (поверхностный шейный, $a$ ) и висцеральном (средостенный каудальный, б) лимфатическом узлах; импрегнация азотнокислым серебром
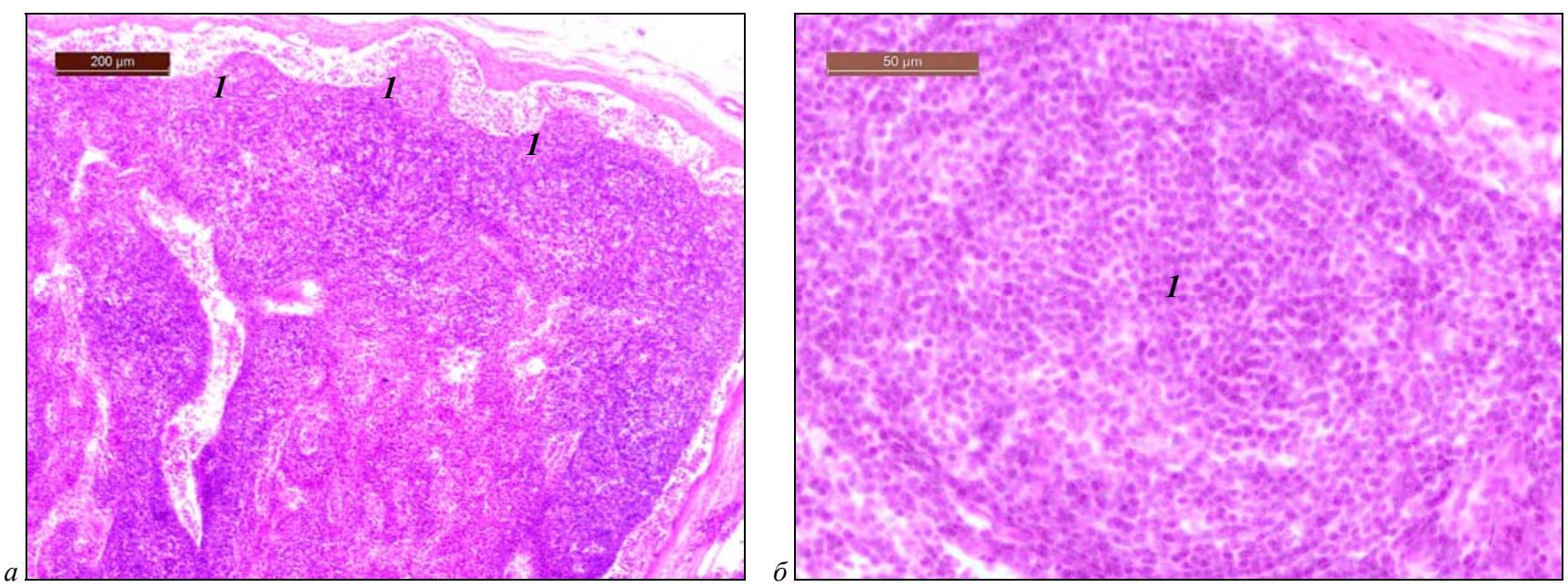

Рис. 7. Лимфатические узелки (1) в интерфолликулярной зоне подмышечного $(a)$ и подвздошноободочного (б) лимфатических узлов; гематоксилин и эозин

В некоторых лимфатических узлах новорожденных телят (и, прежде всего, висцеральных) лимфатические узелки формируются в толще паракортикальных тяжей, что, вероятно, свидетельствует о возможности их развития в любых участках транзитных зон лимфоидных долек. Кроме того, в мозговых тяжах подвздошноободочных лимфатических узлов обнаружи- ваются незначительные утолщения, структура ретикулярной стромы которых аналогична строме лимфатических узелков, расположенных в пределах транзитных зон (рис. 9).

Факт развития лимфатических узелков исключительно на апикальных полюсах лимфоидных долек является приоритетным в большинстве научных публикаций (Rose et al., 1984). 
В то же время гистоструктура и клеточный состав транзитных (интерфолликулярной и паракортикальной) зон, которые фактически являются внешней оболочкой зоны локализации и пролиферации Т-лимфоцитов, являются абсолютно аналогичными. Это в значительной степени объясняет возможность формирования лимфатических узелков в любых участках зон транзита лимфоидной дольки. Наличие узлообразных утолщений в мозговых тяжах висцеральных лимфатических узлов но-

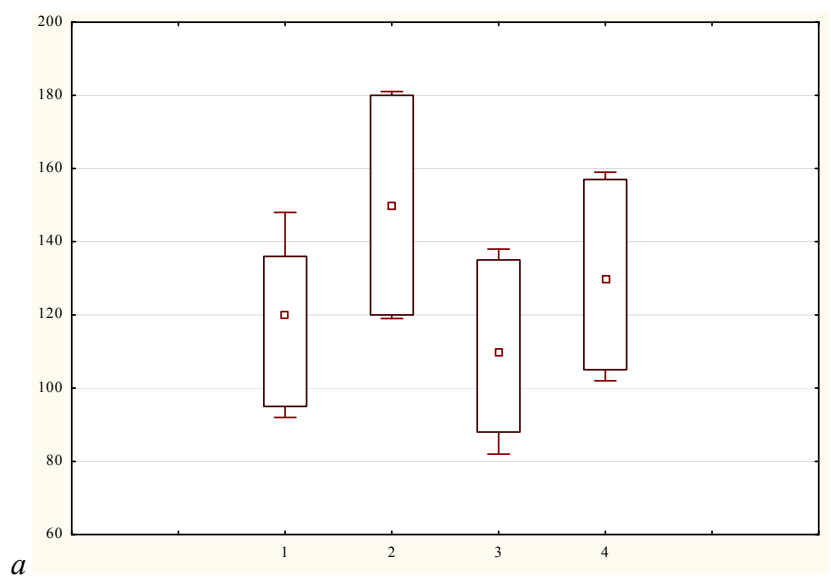

ворожденных телят может свидетельствовать о возможности формирования лимфатических узелков также в зонах преимущественной локализации антителосинтезирующих клеток. Данная особенность висцеральных лимфатических узлов описана в отдельных публикациях, где указывается, что она может быть обусловлена усиленной антигенной стимуляцией лимфатических узлов, регионарных для тонкого кишечника (Törö and Csaba, 1970; Sapin et al., 1978).

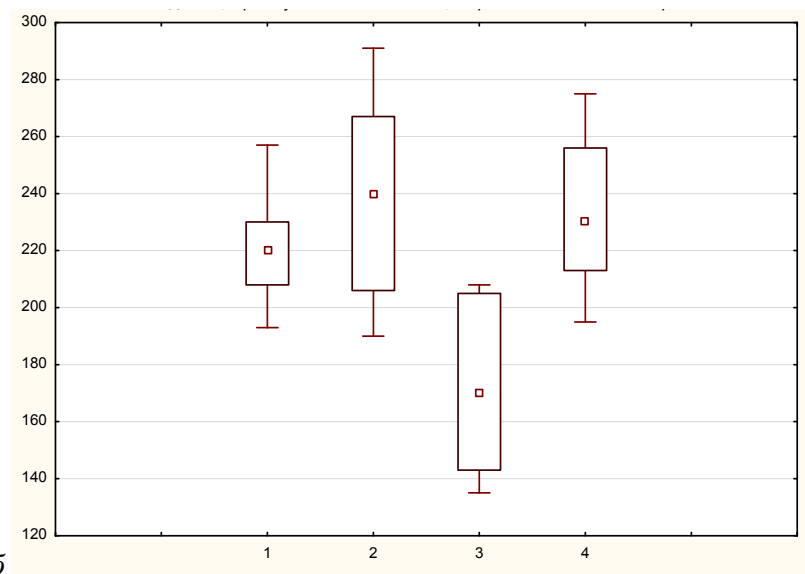

Рис. 8. Диаметр лимфоидных узелков (мкм): $a$ - соматические лимфатические узлы (поверхностные: 1 - поверхностный шейный, 2 - подподвздошный), глубокие (3 - подмышечный, 4 - подколенный); 6 - висцеральные лимфатические узлы ( 1 - каудальный средостенный, 2 - подвздошноободочный), соматовисцеральные (3 - медиальный подвздошный, 4 - медиальный заглоточный); по оси абсцисс - лимфатические узлы, по оси ординат - диаметр лимфоидных узелков (мкм)
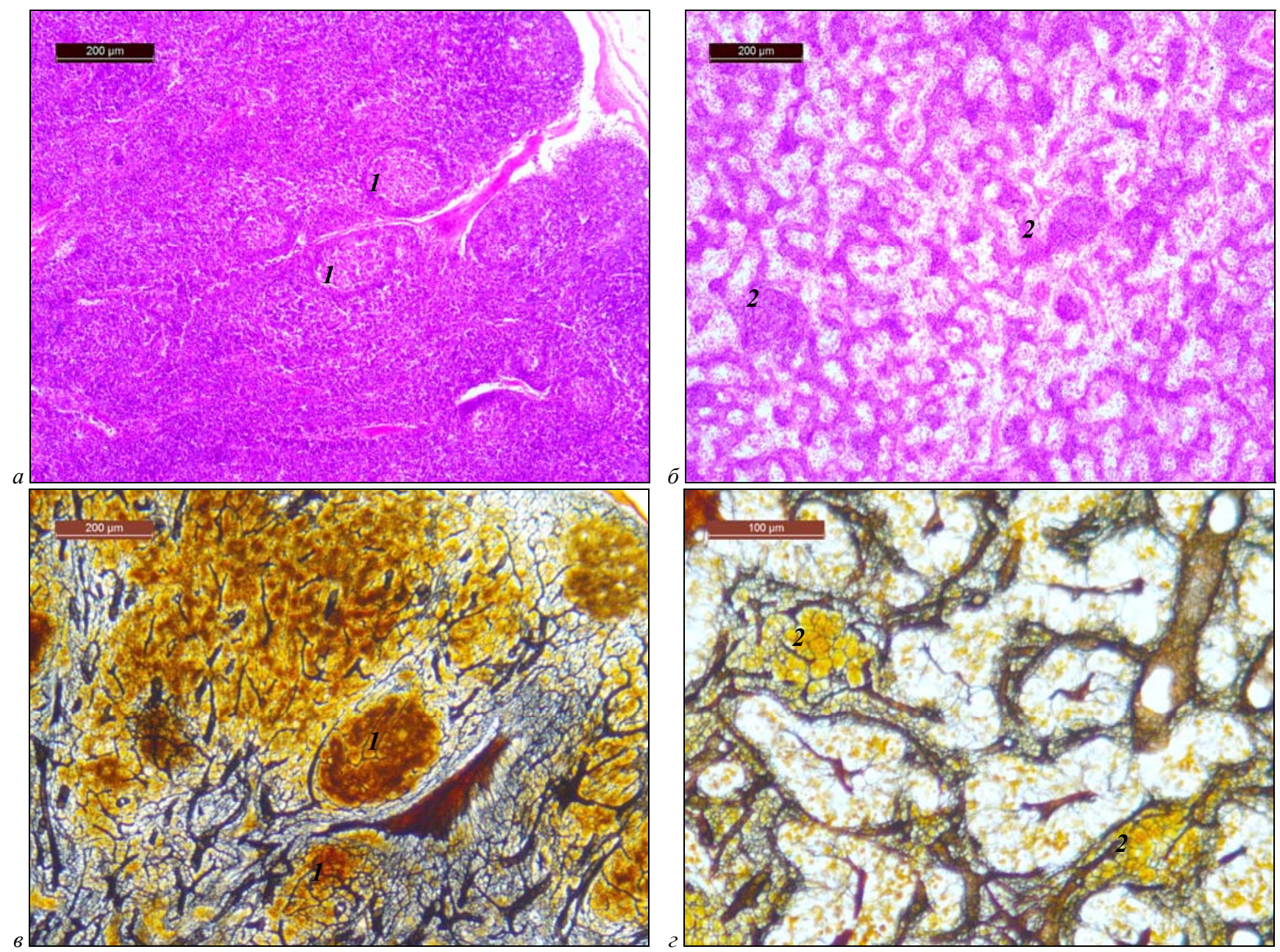

Рис. 9. Лимфатические узелки (l) в паракортикальных тяжах каудального средостенного $(a, b)$ лимфатического узла: узлообразные утолщения (2) на основе мозговых тяжей подвздошноободочного $(\sigma, 2)$ лимфатического узла; $a, \sigma$ - гематоксилин и эозин,, , 2 - импрегнация азотнокислым серебром 
Таким образом, структурно-функциональными единицами паренхимы лимфатических узлов новорожденных телят быка домашнего являются лимфоидные дольки, которые к моменту рождения достаточно сформированы, имеют ряд характерных черт строения и гистоархитектоники. Высокая степень морфофункциональной зрелости лимфоидной паренхимы у новорожденных особей быка домашнего определяется, вероятно, двумя основными биологическими факторами: наличием у парногопытных наиболее совершенных систем жизнеобеспечения в целом и зрелорождаемостью или матуронатностью как одной из характерных черт организменного статуса копытных млекопитающих. У новорожденных имматуронатных видов млекопитающих в паренхиме лимфатических узлов отсутствуют признаки структурно-функциональной дифференциации и зональной специализации (Krishtoforova, 2007).

\section{Выводы}

У новорожденных особей быка домашнего паренхима лимфатических узлов отличается высокой степенью морфофункциональной дифференциации и имеет выраженную дискретную структуру с подразделением на лимфоидные дольки (компартменты), которые представлены комплексом отдельных специализированных зон в виде тяжей лимфоидной ткани (интерфолликулярные, паракортикальные и мозговые тяжи) и сферообразных лимфоидных структур (центральные зоны единиц глубокой коры и лимфатические узелки). Количественные характеристики компонентов лимфоидных долек в различных группах лимфатических узлов значительно варьируют. Они максимальны в висцеральных лимфатических узлах и минимальны в глубоких соматических.

Наиболее развитыми компонентами лимфоидных долек (компартментов) лимфатических узлов новороженных особей быка домашнего являются перисинусоидальные тяжи лимфоидной ткани (интерфолликулярные, паракортикальные, мозговые). Среди сферообразных (округлых) клеточных зон во всех исследованных группах узлов преобладают участки клональной пролиферации Т-лимфоцитов (центральные зоны единиц глубокой коры), а в целом специализированные клеточные зоны максимально развиты в лимфатических узлах кожи и слизистых оболочек и минимально - в глубоких соматических лимфатических узлах.

В пределах каждой лимфоидной дольки наиболее стабильными в топографическом отношении компонентами являются перисинусоидальные тяжи лимфоидной ткани, затем следуют центральные зоны единиц глубокой коры, которые могут формировать дочерние структуры (боковые выпячивания). Наиболее лабильными компонентами лимфоидных долек являются лимфатические узелки, локализующиеся в любом участке тяжей лимфоидной ткани коры узлов и в мозговых тяжах.

Дальнейшие исследования особенностей структуры паренхимы лимфатических узлов быка домашнего будут направлены на изучение закономерностей развития компартментов паренхимы узлов в постнатальном онтогенезе, в том числе при различных технологиях выращивания животных и, соответственно, различной интенсивности и характере действия антропогенных факторов.

\section{References}

Ager, A. (2017). High endothelial venules and other blood vessels: Critical regulators of lymphoid organ development and function. Frontiers in Immunology, 8(3), 1-16.

Andrian, U. H., \& Mempel, T. R. (2003). Homing and cellular traffic in lymph nodes. Nature Reviews Immunology, 3, 867-878.

Avtandilov, G. G. (1990). Meditsinskaya morfometrya [Medical morphometry]. Medicine, Moscow (in Russian).

Azzi, J., Yin, Q., Uehara, M., Ohori, S., Tang, L., Cai, K., Ichimura, T., McGrath, M., Maarouf, O., Kefaloyianni, E., Loughhead, S., Petr, J., Sun, Q., Kwon, M., Tullius, S., von Andrian, U. H., Cheng, J., \& Abdi,
R. (2016). Targeted delivery of immunomodulators to lymph nodes. Cell Reports, 15(6), 1202-1213.

Belisle, C., \& Sainte-Marie, G. (1981). Tradimentional study of the deep cortex of the rat lymph node. III. Morphology of the deep cortex units. The Anatomical Record, 199(2), 213-226.

Buhvalder, R., Fuks, H., \& Hayder, G. (1981). Osnovyi immuniteta. Immunoprofilaktika bolezney zhivotnyih [The basis of immunity. Immunoprophylaxis of animal diseases]. Kolos, Moscow (in Russian).

Butler, J., Sawtell, A., Jarrett, S., Cosgrove, J., Leigh, R., Timmis, J., \& Coles, M. (2016). Imaging immunity in lymph nodes: Past, present and future. Advances in Experimental Medicine and Biology, 915, 329-346.

Capece, T., \& Kim, M. (2016). The role of lymphatic niches in T cell differentiation. Molecules and Cells, 39(7), 515-523.

Chandrasekaran, S., \& King, M. R. (2014). Microenvironment of tumor-draining lymph nodes: Opportunities for liposome-based targeted therapy. International Journal of Molecular Sciences, 15(11), 20209-20239.

De Bruyn, P. P., \& Cho, Y. (1990). Structure and function of high endothelial postcapillary venules in lymphocyte circulation. Current Topics in Pathology, 84(1), 85-101.

Elmore, S. A. (2006). Enhanced histopathology of the lymph nodes. Toxicologic Pathology, 34(5), 634-647.

Emelyanenko, P. A. (1987). Immunologia zhivotnych v period vnytriutrobnogo razvitia [Immunology of animals in the period of intrauterine development]. Agropromizdat, Moscow (in Russian).

Gavrilin, P. N. (1999). Modificatsiya sposoba impregnatsii serebrom po Futy gistotopogramm organov krovetvoreniya, izgotovlennyih na microtomekriostate [Modification of the silver impregnation method according to Fut histotopograms of hemopoietic organs made on a microtome cryostat]. Vestnik Morphologii, 5(1), 106-108 (in Russian).

Gavrilin, P. N. (2000). Osoblyvosti dynamiky masy limfoi'dnyh organiv u teljat neonatal'nogo i molochnogo periodiv [Features of the dynamics of the mass of lymphoid organs in neonatal and dairy calves]. Agrarnyj Visnyk Prychornomorya, 4(9), 24-29 (in Ukrainian).

Gavrilin, P. N., Prokushenkova, O. H., Masjuk, D. N., \& Perepechaeva, N. H. (2013). Peculiarities of structural and functional organization of Domestic Bull's lymph nodes parenchyma (Bos primigenius taurus L.). Naukovyj Visnyk Nycionalnogo Universytetu Bioresursiv i Pryrodokorystuvannja Ukrainy, 188(1), 92-101 (in Ukrainian).

Geptner, V. C., Naumov, N. P., \& Jurgenson, P. B. (1961). Mlekopitajushhie Sovetskogo Sojuza. Parnokopytnye i mozolenogie [Mammals of the Soviet Union. Clovenhoofed and soliped]. Moscow (in Russian).

Gretz, J. E., Anderson, C. C., \& Shaw, S. (1997). Cords, channels, corridors and conduits, critical architectural facilitating cell interactions in the lymph node cortex. Immunological Reviews, 156, 11-24.

Gunnes, G., Press, C., Tverdal, A., \& Landsverk, T. (1998). Compartments within the lymph node cortex of calves and adult cattle differ in the distribution of leukocyte population: An immunohistochemical study using computer-assisted morphometric analysis. Developmental and Comparative Immunology, 22(1), 111-123.

Hoshi, N., Hashimoto, Y., Kitagawa, H., Kon, Y., \& Kudo, N. (1986). Histological and immunohistochemical studies on the architecture of lymph nodes in pig. Japan Journal Veterinary Science, 48(6), 1097-1107.

Houston, S. A., Cerovic, V., Thomson, C., Brewer, J., Mowat, A. M., \& Milling, S. (2016). The lymph nodes draining the small intestine and colon are anatomically separate and immunologically distinct. Mucosal Immunology, 9(2), 468-478.

Ikomi, F., Kawai, Y., \& Ohhashi T. (2012). Recent advance in lymph dynamic analysis in lymphatics and lymph nodes. Annals of Vascular Diseases, 5(3), 258-268.

Iwasaki, R., Mori, T., Ito, Y., Kawabe, M., Murakmi, M., \& Maruo, K. (2016). Computed tomographic evaluation of presumptively normal canine sternal lymph nodes. Journal of the American Animal Hospital Association, 52(6), 371-377.

Jafarnejad, M., Woodruff, M. C., David, C. Z., Michael, C. C., \& Moore, J. E. (2015). Modeling lymph flow and fluid exchange with blood vessels in lymph nodes. Lymphatic Research and Biology, 13(4), 234-247.

Jia, L., Xie, Z., Zheng, J., Liu, L., He, Y., Liu, F., \& He, Y. (2012). Morphological studies of lymphatic labyrinths in the rat mesenteric lymph node. The Anatomical Record, 295, 1291-1301.

Kaldjian, E. P., Gretz, J. E., Anderson, A. O., Shi, Y., \& Shaw, S. (2001). Spatial and molecular organization of lymph node T cell cortex: A labyrinthine cavity bounded by an epithelium-like monolayer of fibroblastic reticular cells anchored to basement membrane-like extracellular matrix. International Immunology, 13(10), 1243-1253.

Katakai, T., Hara, T., \& Lee, J. H. (2004). A novel reticular stromal structure in lymph node cortex: An immuno-platform for interactions among dendritic cells, T cells and B cells. International Immunology, 16(8), 1133-1142. 
Kelly, R. H. (1975). Functional anatomy of lymph nodes. The paracortical cords. International Archives of Allergy and Immunology, 48(6), 836-849.

Koljakov, J. E. (1986). Veterinarnaja immynologija [Veterinary immunology]. Agropromizdat, Moscow (in Russian).

Konenkov, V. I., Shkyrat, G. A., \& Kolesnikov, A. P. (2008). Limfaticheksij uzel: Morfofunkcional'naja harakteristika i mezhkletochnaja kooperacija [Lymph node: Morphofunctional characteristic and intercellular cooperation.]. Vestnik Limfologii, 4, 35-43 (in Russian).

Kowala, M. C., \& Schoefi, G. I. (1986). The popliteal lymph node of the mouse: Internal architecture, vascular distribution and lymphatic supply. Journal of Anatomy, 148(1), 25-46.

Krishtoforova, B. V., Lemeshenko, V. V., \& Stegnej, Z. G. (2007). Biologichni osnovy veterynarnoi' neonatologii' [Biological basis of veterinary neonatology]. Simferopol (in Ukrainian).

Lee, C. M., Park, D. W., Park, S., Kim, J. H., Park, S. H., \& Kim, C. S. (2017). Lymph node dissection using bipolar vessel-sealing device during reduced port laparoscopic distal gastrectomy for gastric cancer: Result of a pilot study from a single. Journal of Laparoendoscopic and Advanced Surgical Techniques, 2017, 27.

Margaris, K. N., \& Black, R. A. (2012). Modelling the lymphatic system: Challenges and opportunities. Journal of the Royal Society Interface, 69, 1-12.

Nicander, L., Nafstad, P., Landsverk, T., \& Engebretsen, R. H. (1991). A study of modified lymphatics in the deep cortex of ruminant lymph nodes. Journal of Anatomy, 178, 203-212.

Ohtani, O., \& Ohtani, Y. (2008). Structure and function of rat lymph nodes. Archives of Histology and Cytology, 71(2), 69-76.

Olson, M. R., McDermott, D. S., \& Varga, S. M. (2012). The initial draining lymph node primes the bulk of the CD8 T cell response and influences memory $\mathrm{T}$ cell trafficking after a systemic viral infection. PLOS Pathogens, $8(12), 1-15$.

Palm, E. A., Friedrich, C. H., \& Kleinau, S. (2016). Nodal marginal zone B cells in mice: A novel subset with dormant self-reactivity. Scientific Reports, 6(27687), 1-11.

Platt, A. M., \& Randolph, G. J. (2013). Dendritic cell migration through the lymphatic vasculature to lymph nodes. Advances in Immunology, 120, 51-68.

Rouse, R. V., Reichert, R. A., Gallatin, W. M., Weissman, I. L., \& Bucher, E. C. (1984). Localization of lymphocyte subpopulation in peripheral lymphoid organs: Directed lymphocyte migration and segregation into specific microenvironments. American Journal of Anatomy, 170, 391-405.

Ruddle, N. H. (2016). High endothelial venules and lymphatic vessels in tertiary lymphoid organs: Characteristics, functions, and regulation. Frontiers in Immunology, 9(7), 1-7.

Sainte-Marie, G. (2010). The lymph node revisited: Development, morphology, functioning, and role in triggering primary immune responses. Anatomical Record, 293(2), 32-37.

Sapin, M. R. (2006). Osobennosti imunnogo otveta pri razlichnych vnechnich vozdeistviyah [Features of the immune response under various external influences]. Morphology, 129(4), 109-110 (in Russian).

Sapin, M. R., Jurina, N. A., \& Etingen, L. (1978). Limfaticheskij uzel [Lymph node]. Medicine, Moscow (in Russian).

Sasaki, K., Okouchi, Y., Rothkotter, H. J., \& Pabst, R. (1996). Ultrastructural localization of the intercellular adhesion molecule (ICAM-1) on the cell surface of hight endothelial venules in lymph nodes. Anatomical Record, 244(1), 105-111.

Shipman, W. D., Dasoveanu, D. C., \& Lu, T. T. (2017). Tertiary lymphoid organs in systemic autoimmune diseases: Pathogenic or protective? F1000Res., 28(6), 1-7.

Sixt, M., Kanazawa, N., Selg, M., Samson, T., Roos, G., Reinhardt, D. P., Pabst, R., Lutz, M. B., \& Sorokin, L. (2005). The conduit system transports soluble antigens from the afferent lymph to resident dendritic cells in the T-cell area of the lymph node. Immunity, 22(1), 19-29.

Törö, Y., \& Csaba, J. (1970). Az ember normalis es pathologies fejlodese [The human pathologies and normal development]. Budapest (in Hungarian).

Vyrenkov, Y. E., Shishlo, V. K., Antropova, J. G., \& Ryzhova, A. V. (1995). Sovremennye dannye o strukturno-funkcional'noj organizacii limfaticheskogo uzla [Modern data on the structural and functional organization of the lymph node]. Morphology, 103(3), $34-40$ (in Russian).

Willard-Mack, C. L. (2006). Normal structure, function, and histology of lymph nodes. Toxicologic Pathology, 34(5), 409-424.

Zelenevsky, N. V. (2013). Mezhdunarodnaja veterinarnaja anatomicheskaja nomenklatura na latinskom i russkom jazykah. Nomina Anatomica Veterinaria [International veterinary anatomical nomenclature in Latin and Russian. Nomina Anatomica Veterinaria]. Mir, Sankt-Peterburg (in Russian).

Zidan, M., \& Pabst, R. (2012). Histological, histochemical and immunohistochemical study of the lymph nodes of the one humped camel (Camelus dromedarius). Veterinary Immunology and Immunopathology, 145, 191-198. 